\title{
Formar, não treinar: o lugar da palavra'
}

\begin{abstract}
Maria Inês Rosa*
Resumo: Indiscriminam-se a formação(formar) e o treinamento(treinar), cada vez mais de modo generalizado e arraigado, quer no sistema de ensino regular, quer fora dele, no social, no momento presente, na sociedade brasileira. Com isso não há distinção entre ambos, tampouco entre as especificidades que os configuram. Preocupamo-nos em distinguir forma[r]ção e treina[r] namento sob a problemática do "sujeito". Nesta distinção é destacado que a língua - a palavra - se situa no domínio da formação e esta, no da transmissão de conhecimentos, em que tem lugar a permanente tensão das dimensões do tempo criador (subjetivo) e de média da norma ao aceder-se aos conhecimentos; já a comunicação destes coloca-se no âmbito do treinamento, com a prevalência da segunda dimensão da norma nesse acesso. Aí a língua é reduzida a instrumento. É graças a essa distinção que são considerados os denominados "cursos" de "treinamento", de "capacitaçăo", de "atualizaçāo" e/ou de "reciclagem" e cursos a distância/não presenciais.
\end{abstract}

Palavras-chave: formar; treinar; língua, transmissão; comunicação; norma.

Educate, not train: the place of the word

Abstract: Education (to educate) and training (to train) have become increasingly more indistinct from one another in a broad and widespread manner, whether in the regular school system or outside it, in the current Brazilian society. As a result, no differences remain between them and their distinguishing features have become blurred. We are concerned about making a distinction between education (to educate) and training (to train) from the standpoint of the "subject". Under this differentiation, language - the word- belongs to the domain of education, which, in turn, belongs to the domain of knowledge transmission, where a permanent tension exists between the dimensions of creating time (subjective) and those of the average rule when a person has access to knowledge, whereas the communication of knowledge belongs to the domain of training and the second dimension of the rule prevails in this process of having access to knowledge. In this case, language is reduced to becoming an instrument. In the light of this differentiation, the so-called "training courses", "skill-enhancing courses", "update courses and/or "refresher courses" and "distance learning courses/courses, which lack the physical presence of the teacher", are evaluated.

Key words: educate; train; language; transmission; communication; rule.

*. Socióloga e Doutora em Sociologia (USP) e Professora Livre-Docente (Unicamp), aposentada. SãoPaulo, SP, Brasil.mirosa@uol.com.br

I. O presente artigo foi elaborado em 14/08/2007 e apresentado ao Seminário Comunicação e Trabalho: Pluridisciplinaridade, Interfaces, Mediações, GPCT/ECA-USP, 23-24/08/2007, tendo sido feitos alguns acréscimos julgados necessários à publicação. 
Introdução

É recorrente a referência a formação como treinamento, quer na empresa, quer fora dela, no social. Ela se desdobra em uma outra, a necessidade de fazer "cursos" ou "cursinhos" de treinamento com vistas a melhor colocar-se no mercado de trabalho, o mesmo ocorrendo com os chamados "cursos" de "atualização", também ditos de "reciclagem". Estes últimos são ainda considerados sob o aspecto de melhoria de formação. Essas referências dão-se sob a égide da transmutação da formação em treinamento, acreditando-se que formar é treinar. Nessa transmutação, o ser vivo humano é situado na condição estrita de agente, porque se exclui a sua outra dimensão, a de "sujeito". Na qualidade de agente, ele portaria coisas que são adquiridas na qualidade de mercadorias, aí compreendidos os conhecimentos. Como tais, estes são reduzidos ao utilitarismo, com a finalidade de serem usados, consumidos, no processo produtivo imediato e em geral. O treinamento é o móvel dessa aquisição e de realização desse caráter.

Para o entendimento dessa transmutação, procuraremos apreender a distinção entre formar e treinar. Nesta distinção, veremos que a língua - a palavra e sua atividade se situam no domínio da formação e/ou do formar e da transmissão; a comunicação coloca-se no domínio do treinamento e/ou do treinar. Do lado das primeiras, têm-se: a relação ao outro ou em direção ao outrol "sujeito" esta relação é a língua -, a dimensão do tempo criador da norma ou a dimensão subjetiva da norma, em que o "sujeito" conflui com o agente e vice-versa, e a atividade de pensar e a de conhecer dão-se, concomitantemente; do lado das segundas, têm-se: a língua tornada móvel ou instrumento de comunicação e a dimensão de média da norma, com as prevalências do agente, graças à exclusão do "sujeito" e da atividade de pensar. A norma, em sua dimensão do tempo criador, é incomensurável, ao contrário da norma em sua dimensão de média, é ela comensurável e, pois, mensurável.

Essas duas dimensões da norma não são excludentes, porque se interpenetram e são interdependentes, porém cada uma guarda suas especificidades na relação com o código da língua e com os conhecimentos por ele portados. No uso do código, a dimensão do tempo criador da norma intenta, sempre, renormalizálo e/ou reelaborá-lo ou, ainda, retrabalhá-lo, dando novos significados aos seus sentidos. Por sua vez, a dimensão de média da norma empreende normatizá-lo e reproduzi-lo mediante as padronizaçôes e as generalizações de seus procedimentos e dos protocolos nele contidos. Isso significa que há tensão constante entre ambas as dimensões e, consequentemente, entre língua e comunicação; e, no caso em questão, entre formação e treinamento. 
Nessa rede de tensão, há a tendência à prevalência da comunicação sobre a língua, quer no âmbito da empresa, quer no social, o que explicaria a dominância daquelas referências e de suas práticas. Ressalte-se, todavia, que essa tendência somente se faz pela linguagem ou pela língua, que é aquela relação - relação ao outro/"sujeito" . A prevalência tem lugar graças àquela redução da língua, ou seja, redução a instrumento ou móvel de comunicação de conhecimentos tidos como estritamente utilitários e enquanto dados e acabados para serem apropriados e consumidos. Nessa condição, conforme acima apontado, os conhecimentos nada mais seriam do que coisas, mercadorias, para que sejam portadas pelo agente que as adquiriu. Assim, os conhecimentos não são transmitidos, mas comunicados, sem o retrabalho da dimensão do tempo criador da norma, quer por quem os exprime, quer por quem os escuta e os aprende. Disso decorre que a transmissão se torna comunicação desses conhecimentos já acabados e não passíveis de questionamentos e reelaboração que efetuaria o "sujeito" mediante esse retrabalho.

Alguns momentos da formação e do treinamento serão aqui considerados. Eles tiveram lugar em uma unidade fabril de uma empresa do ramo MetalMecânico do setor Metalúrgico da cidade de São Paulo, na década de 90 do século passado. Todavia, esses momentos transcendem esse tempo e lugar em virtude da prevalência dessa tendência e de sua generalização no social, no momento presente. Esses momentos são dados a conhecer pelos trabalhadores, operários e não operários, por meio de seus testemunhos. Eles ocorreram por ocasião das mudanças no uso de $\mathrm{Si}$, no uso do Ser vivo humano, no trabalho. ${ }^{2}$ Essas mudanças, que impunham um novo modo de trabalho, vieram configurando-se desde o fim da década de 70, cujo auge foi a década de 90 do século passado e o início do presente século. Escolheu-se, dentre esses testemunhos, um que é representativo desses momentos. Suas palavras são a testemunha da distinção entre formar e treinar.

\section{Linguagem e ensino: palavra e formação}

Esses momentos da formação e do treinamento reportam à situação de trabalho em sala de aula, na própria empresa. Esta situação nos conduz para a apreensão da distinção entre forma[r]ção e treina[r]mento. É o trabalhador, nas funções de Instrutor e Inspetor de Qualidade, quem dela dá testemunho.

2. Baseamo-nos em nossa pesquisa de Livre-Docência (Rosa, 2004). Nela privilegiamos a perspectiva filosófica e ergológica construída por Schwartz, porém considerando outros interlocutores. Neste artigo, procedemos igualmente. O leitor interessado encontrará, no livro, os esclarecimentos, as citações literais, por vezes longas, feitos de modo exaustivo, com o intuito de que o leitor se aproximasse dessa perspectiva e a conhecesse. Dela consta vasta bibliografia. 
Ressalte-se que, por ocasião da situação de trabalho de entrevista (Rosa, 2004, p. 77-121), em sua casa, em 11/12/1993, ele se apresentara enquanto Instrutor e, secundariamente, como Inspetor de Qualidade. Entretanto, as atividades principais que realizava, no setor de Produção, estavam adstritas a esta última função. Em 1998, no retorno à pesquisa de campo, ao ser contatado, pelo telefone, assim se expressou:

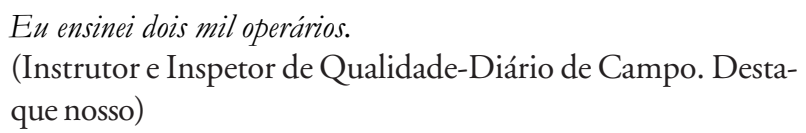

Nesse momento, ganha sentido pleno essa sua apresentação, ao não fazer mais o uso da linguagem do código do trabalho prescrito (da língua do código desse trabalho) que o nomeava como Instrutor, ao ensinar os conhecimentos das disciplinas Matemática (denominada de Matemática I e II), Desenho (denominada de Desenho I e II), Metrologia e o curso CEP (Controle de Estatística e Processos). Ele fez uso da língua ${ }^{3}$ e/ou uso da atividade de linguagem e, nela, exprimiu a dimensão do tempo criador da norma, ao situar-se e apresentar-se como quem ensina - o Professor. Retomaremos, logo a seguir, o uso da língua.

Sobre essa atividade de ensinar, manifestou o sentimento:

$$
\begin{aligned}
& \text { Eu sinto tanta saudade, mas tanta saudade. } \\
& \text { (Instrutor e Inspetor de Qualidade - Diário de campo). }
\end{aligned}
$$

O Instrutor e Inspetor de Qualidade, que ora em diante chamaremos de Professor (também renormalizamos, como ele, esse código, isto é, fizemos uso da atividade de linguagem e da dimensão subjetiva e/ou do tempo criador da norma), alude a sua atividade de ensinar na situação de trabalho na sala de aula, situada no interior da empresa. Fora aí que ensinara aqueles "dois mil operários”, e desta atividade ressalta:

Nós temos que ensinar para eles raiz quadrada, que não épermitido usar calculadora. Por quê? Porque eles vão ter que fazer teorema de Pitágoras e fazer trigonometria. Enós temos também adição e subtração de grau, minuto, segundo. Então, veja bem, vocêse imagine só, uma pessoa que não tem primário, ele não sabe nem tabuada,

3. Sobre o uso da língua, cf. Elias ( 1994 , passim), ao longo do livro o autor analisa, sociológica e filosoficamente, esse uso e o seu compartilhar pelos seres humanos nos desenvolvimentos biológico, cultural, social, sob o crivo do processo de longa duração, da história, das relações humanas; Schwartz (1 988, p. 224-233) também o analisa, na perspectiva filosófica e ergológica; também Rosa (2004, p. I 50-253) o faz, na interlocução com ambos os autores, considerando os testemunhos de trabalhadores. 
você [...] tentar ensinar uma matéria dessa para ele! Então, é uma dificuldade [...] é uma coisa de muita dificuldade. (Instrutor e Inspetor de qualidade. Destaques nossos).

O Professor testemunha que na atividade real de trabalho de ensinar há a primazia da palavra na relação entretida com o aluno-operário. Isto porque "[...] A língua. Quer dizer a relação ao outro" (Lacoue-Labarthe, 1986, p. 57, apud Landa, 2002, p. 12) ${ }^{4}$ ou a língua é a relação ao outro.

É essa relação que o Professor nos dá a conhecer nessa atividade de trabalho, fazendo uso da língua - de seu código ou sistema de símbolos sonoros padronizadores e de seus sentidos (Elias, 1994, p. 62-83; Rosa, 2004, p. 191) na(s) e pela(s) palavra(s). Como destacado acima, ele fez uso da língua, pela atividade de linguagem (palavra), de acordo com Schwartz (1988, p. 224233), ou pela linguagem, conforme Elias (1994). Uso este que se dá pela(s)/ na(s) palavra(s), construindo essa relação e dando significados a esses sentidos. A palavra é tecedora dessa relação humana e do compartilhar comum da língua $^{5}$ e de seu uso. É, pois, a língua, a relação ao outro, ao "sujeito", relação interpessoal. Ela é construída ao longo do texto mediante a palavra ${ }^{6}$ que nos aproxima do "sujeito" na atividade real de trabalho de ensinar, remetendo-nos à problemática do "sujeito" ${ }^{7}$. Assim, é por meio dessa relação particular que é a língua, que o Professor afirma o quanto é difícil "ensinar uma matéria dessa para ele" (aluno-operário), "é uma dificuldade", bem como o conduz a manifestar aquele sentimento de "tanta saudade".

É ainda essa relação ao outro que é a língua que o faz constatar a privação dos conhecimentos regulares do nível de ensino fundamental de seu aluno: "que não tem primário, ele não sabe nem tabuada [...] é uma coisa de muita dificuldade".

Essas palavras destacadas são a testemunha da primazia da palavra e, pois, dessa relação humana. Essa relação coloca a descoberto que a atividade de trabalho de ensinar se dá no (re)conhecimento ${ }^{8}$ do outro em seus possíveis singulares, no caso, o dessa privação e dessa "[...] muita dificuldade (de ensinar)". Em

4. Landa (2002) constrói essa relação nesse seu artigo.

5. Cf. nota 3.

6. Cf. Rosa (2008), onde apresentamos também essa construção.

7. O termo "sujeito" é colocado entre aspas porque suas subjetividades individual e social são sempre inacabadas, tal qual a sociedade humana, de acordo com Elias (199I, p. 67, p. 85-86, p. 107-108, p. |44-|45). A problemática do "sujeito" é tecida pela interlocução com os autores apresentados, ao longo do texto, e na mediação dessa relação humana particular.

8. Nos chamados cursos a distância e/ou não presenciais há a ausência desses (re)conhecimento e, portanto, há a ausência do que estamos caracterizando como atividade de trabalho de ensinar. Retomaremos essa observação no final do artigo: À guisa de conclusão. 
virtude disso, a atividade real de trabalho de ensinar coloca como condição sine qua non a presença do outro, sua manifestação, nessa relação: a de quem ensina e a de quem é ensinado, ou seja, do "sujeito".

Convocado por essa condição inelutável, ele, o Professor, se interroga:

\begin{abstract}
Então, o quê que você tinha que fazer? [...] tinha que, primeiro de tudo, você arrumar um jeito de você dar aula, tentar dar aula para eles [...]. Então, eu pegava esses alunos que o grau de dificuldade era maior e trazia eles perto de mim [...] porque se você conhece, vocêtem uma sala de aula com 30...30 lugar para sentar, o quê que eles vão fazer? (os alunos com esse "grau de dificuldade maior") [...] (vão) sentar lá embaixo, perto da parede. (Instrutor e Inspetor de Qualidade. Destaques nossos).
\end{abstract}

"Trazia eles perto de mim" ou "jeito de você dar aula" são o modo de trabalho que o Professor encontrou para a aproximação dos possíveis singulares dos alunos-operários/do outro - "sujeito" -, manifestos naquela privação de conhecimentos regulares do sistema de ensino e, pois, com "o grau de dificuldade maior". Essa aproximação dá-se mediante a atividade de trabalho real de ensinar. Chama-nos a atenção que aí há um outro (re)conhecimento feito pelo Professor: os das diferentes temporalidades pessoais (ergológicas) que se exprimem na aprendizagem ou no decorrer da formação, através das diferenças de tempo de aprendizagem de cada um dos alunos-operários, como se pode depreender nas palavras a seguir:

Fazer com que se sentissem bem [...] aquele que não entendesse qualquer coisa a gente fazia quantas vezes precisasse, que não tinha pressa, se a pessoa não aprendesse hoje, ia aprender amanhã, não teria problema nenhum [...] eu usava esse caminho ai. (Instrutor e Inspetor de Qualidade. Destaques nossos).

Reitera o Professor o seu modo de trabalho de ensinar, quando afirma "eu usava esse caminho aî". Atesta que não há um único e igual modo de trabalhar, de ensinar, como o quis o taylorismo e como o querem ideários assemelhados atuais de governo do trabalhador, seja este ou não trabalhador-professor. Já as suas palavras, "A gente fazia quantas vezes precisasse", exprimem essas diferenças de temporalidades e de aprendizagem por ele consideradas, nesse modo, para que os alunos-operários "entendesse $(m)$ ".

A palavra "a gente", por ele expressa, declina quem ensina e quem é ensinado na língua, ou seja, ela é a expressão da língua como a relação ao outro, a qual convoca um e outro, de maneira diferenciada, na atividade real de trabalho de ensinar. O Professor é afrontado, no seu trabalho de ensinar, com os conhecimentos de "uma matéria [...] uma coisa de muita dificuldade", enquanto o alu- 
no-operário é afrontado em aceder-lhe, e o faz fincado em seus possíveis singulares, isto é, por meio dessas temporalidades - sua história pessoal, biografia e subjetividade.

A atividade de trabalho real de ensinar também se desenrola fincada nos possíveis singulares de quem ensina; se assim não fosse, essa atividade não teria como primazia a língua, e, pois, essa relação. Nesse sentido, retomemos as palavras ditas pelo Professor, que disso dão testemunho:

$$
\begin{aligned}
& \text { vocêse imagina só uma pessoa que não tem primário [...] porque se } \\
& \text { você conhece, você tem uma sala de aula com } 30 . . .30 \text { lugar para } \\
& \text { sentar, o que eles (os alunos-operários "que o grau de dificuldade } \\
& \text { era maior") vão fazer? [...] (vão) sentar lá embaixo, perto da pare- } \\
& \text { de. (Instrutor e Inspetor de Qualidade) }
\end{aligned}
$$

As palavras "você se imagina" e "você conhece" referem-se a si mesmo na qualidade de Professor; melhor dizendo, referem-se aos seus possíveis singulares na experiência de trabalho de trabalhador-professor que, nessa relação, constrói um modo de trabalho, conforme salientado, à aproximação, pela atividade real de trabalho de ensinar, dos possíveis singulares do aluno-operário, no caso desse "grau de dificuldade" e dessas temporalidades. Essa construção calcada na experiência de trabalho de ensinar só é possível porque é o trabalho experiência (Rosa, 2004, p.178-195; Schwartz, 2000b, p. 335-337), fazendo-se no encontro com os conhecimentos: os epistêmicos, os técnicos e os sociais. Isso ocorre com todo trabalho e não somente com o trabalho de ensinar. Retomaremos mais adiante esse encontro.

Destaque-se, ainda, que na atividade de trabalho real de ensinar é convocado, permanentemente, um outro ou terceiro. Este terceiro é tanto o passado imemorial quanto o mais recente que nós herdamos, o qual nessa atividade concerne a um corpus de conhecimentos específicos a serem ensinados para o aluno-operário: os conhecimentos das disciplinas Matemática, Desenho, Metrologia e o curso CEP (Controle Estatístico de Processos). É graças a essa dupla experiência, a do trabalho como experiência e a da experiência da atividade de trabalho de ensinar que o professor transmite esses conhecimentos, conduzindo o aluno-operário a aceder-lhes. Quer o Professor, quer o aluno, ambos realizam o encontro entre experiência e conhecimentos.

\section{I.2. Transmissão e dimensão subjetiva da norma: encontro entre pensar/ experiência e conhecer/conhecimentos}

A transmissão (Schwartz, 2004, 2005) dos conhecimentos é mediada pela língua que, como sabemos, é a relação ao outro. Por isso o acesso aos conhecimentos torna-se, de imediato, encontro entre experiência e conhecimentos (Rosa, 
2004, p.161-227; Schwartz, 2000b, p. 333-358;) por parte do aluno-operário, o aprendiz. Vale dizer, há o encontro que se ancora naqueles possíveis singulares e nas diferentes temporalidades ergológicas e nos diferentes tempos de aprendizagem dos alunos-operários. É ele o instante que Schwartz (1998, p.101-139) nomeia de encontro entre ingrediente 1 (i1) e ingrediente 2 (i2), respectivamente, entre corpus de conhecimentos (aqueles conhecimentos específicos dessas disciplinas e desse curso e os conhecimentos herdados de um passado remoto, o terceiro) e experiência (o "sujeito", em sua dimensão subjetiva - suas biografia, história e formação, seus possíveis singulares). Na transmissão, na atividade real de trabalho de ensinar, tem lugar, pois, uma relação jamais dual, mas ternária, em virtude mesmo do fato de ela ter como primazia a língua que, sendo essa relação, já porta o terceiro; no caso, o ingrediente 1 (i1), presente e passado. Desse modo, a transmissão desenrola-se sob o crivo dessa relação ternária, desse encontro/instante e das dimensões subjetivas de quem ensina e de quem é ensinado, ou seja, do "sujeito". Nela há o imponderável e a imprescritibilidade do instante em que se efetua o encontro pelo aprendiz. Em outras palavras, o encontro/instante é imprescritível e não capturável e não controlável pela dimensão de média da norma ${ }^{9}$, pela sua normatividade, visto estar ele na dependência dos possíveis singulares, da dimensão subjetiva, de quem o efetua: seja de quem transmite o i1, seja de quem a ele acede e aprende. Todavia, o Professor-trabalhador cria as condiçóes, condensadas num modo de trabalho específico, diante das dificuldades de entendimento do aluno-operário, para que se dê esse instante/encontro e faz com que ele, ao aceder aos conhecimentos, ao i1, entenda-os. Por isso afirma: "aquele que não entendesse qualquer coisa, a gente fazia quantas vezes precisasse".

A nosso ver, essa criação remete à dimensão do tempo criador da norma - a dimensão subjetiva - em que têm lugar os conhecimentos (i1). Mediante a atividade de linguagem, no caso de quem ensina - o professor : o aprendiz é conduzido não somente a conhecer, mas, no mesmo ato, ao entendimento, à reflexão desses conhecimentos transmitidos e à realização desse instante/encontro. É a relação interpessoal da língua, a relação ao outro, que é posta em primeiro plano com vistas ao pensar, ao entendimento e à reflexão sobre as normas antecedentes do corpus de conhecimentos (i1) por parte daquele que aprende. Ou seja: conhece-se a dimensão de média dessas normas, vale dizer, seu caráter generalizador e homogeneizador aportado pelos conhecimentos e pelos respectivos protocolos e procedimentos que lhe corresponde. Entretanto, esses conhecimentos não são tomados pela dimensão do tempo criador da norma como dados e acabados a serem apropriados e utilizados e consumidos

9. Sobre a norma em sua dupla dimensão, de média e de tempo criador, cf. Rosa (2004, p. I 23- I 59). 
como coisas. Ao contrário, são pensados e refletidos. Essas atividades intelectuais são realizadas por quem está aprendendo e/ou sendo ensinado, significando que o aluno, nesse encontro/instante, efetua um trabalho em formação, diríamos um trabalho prévio à atividade real de trabalho, qualquer que venha a realizar. Não haveria aí simplesmente a atividade de conhecer, porém, juntamente, dar-se-ia a atividade de pensar (Arendt, 2004, p. 226-257) ${ }^{10}$. Esta última atividade busca neutralizar esse caráter generalizador e homogeneizador da dimensão de média da norma; mais especificamente, busca neutralizar a sua tendência de negar a dimensão subjetiva e/ou do tempo criador da norma, que é a própria presença do "sujeito" e sua manifestação. Dito de outro modo, esse caráter de média da norma tende a negar e a abstrair essa manifestação - o "sujeito". Há, portanto, na atividade real de trabalho de ensinar, permanente tensão entre ambas as dimensões da norma. No entanto, a dimensão do tempo criador da norma não é subdimensionada nem subsumida pela outra dimensão da norma, a de média. Se tal ocorresse, não haveria o encontro entre experiência e conhecimentos, que torna essa atividade formação de outrem/ formar outrem - atividade de trabalho de forma[r]ção do "sujeito", em que o trabalho é experiência.

\section{Treinamento e comunicação: instrumentalização da palavra}

Retomemos as palavras do testemunho do Professor, através das quais destacamos na atividade de trabalho real de ensinar a língua e, dentre outros aspectos examinados, chamamos a atenção tanto para a tensão entre as dimensões da norma- a de média e a do tempo criador- e para a interdependência e para a interpenetração de ambas, quanto para a interdependência da atividade de pensar e da atividade de conhecer.

Agora, porém, situá-las-emos como testemunhas dessa tensão, referindonos ao contexto da situação de trabalho na unidade fabril onde ocorriam as mudanças no uso de Si - do Homem ou do Ser vivo humano -, na condição de trabalhador, mediante o novo modo de trabalho ou o novo governo do trabalho. Aí tinha lugar a pressão sobre o operário, como aluno, para que obtivesse a média 7,5 (sete e meio) ao término de cada disciplina e curso realizados e, caso não a alcançasse, ele seria dispensado.

As palavras são: "fazer com que se sentissem bem [...] que não tinha pressa". Elas aludem também a esse clima de ameaça de dispensa vivido pelo alunooperário. Na realidade, a dispensa não acontecia de imediato, ela ocorria somente após a segunda tentativa de realização das disciplinas e cursos por parte do aluno-operário. Não obtendo essa média, ele era transferido para outro

10. Cf. a distinção entre atividade de conhecer e atividade de pensar efetuada por Arendt (2004). 
setor e depois dispensado. Isso porque o novo modo de trabalho exigia, como já salientado, os conhecimentos dessas disciplinas (i1), e num tempo "estrito". E, para tanto, fazia abstração daquelas temporalidades pessoais e daqueles diferentes tempos de aprendizagem do aluno-operário. Vale dizer, abstraía-se o "grau de dificuldade" de cada aluno-operário. Esses conhecimentos, que também são normas antecedentes desse novo modo, constituem o código da língua do trabalho prescrito e são imprescindíveis para a sua realização. Conhecêlos é aceder à dimensão de média da norma, ou seja, é aceder a esses conhecimentos exigidos, contudo nesse tempo estrito, o qual também integra o código. Eis o porquê da vivência da ameaça de dispensa e consequente perda do emprego pelo operário, se reprovado consecutivamente nos cursos.

Ressaltamos que a exigência de aprendizagem desse código está sob a dominância desse tempo estrito, regido pela temporalidade econômica mercantil capitalista, que determina a duração de cada disciplina e curso graças a essas abstrações. Desse modo, as palavras "que não tinha pressa" aludem àquela pressão e a essa dominância, com as quais se defrontam o Professor e os alunosoperários. Essas palavras também aludem a esse temor da dispensa.

É, ainda, sob a égide dessas pressão e dominância que a atividade real de trabalho de ensinar, que é a de formação, é reduzida à atividade real de trabalho de treinar. Esta última atividade empreende a suspensão do encontro/instante entre conhecimentos e experiência pela dimensão do tempo criador da norma e, assim, a língua torna-se móvel ou instrumento para comunicar o corpus de conhecimentos (i1) das disciplinas Matemática, Desenho, Metrologia e curso CEP. Conforme já destacamos, esses conhecimentos, sob o crivo da dimensão de média da norma do novo modo de trabalho, são tidos como absolutamente irretorquíveis e não passíveis de retrabalho pela dimensão do tempo criador da norma. Aí o encontro nada mais seria do que a experiência reduzida a conhecer esse corpus de conhecimentos e as exigências à consecução do novo modo de trabalho. Todavia, essa dimensão, a do tempo criador da norma, como vimos, é imprescritível, por ser da ordem do "sujeito", de sua temporalidade ergológica (pessoal) e de seus possíveis singulares, o que significa que ela não se enquadra sob essa dimensão normativa. Contudo, esta última a suspende e também a subsume e a subdimensiona. Através da antecipação que efetua, ancorada nesse corpus de conhecimentos, a dimensão de média da norma opõese à antecipação que a dimensão do tempo criador da norma empreende - seu retrabalho dessa dimensão normativa - e com ela se conflita, na relação de interdependência entretida. Essa tensão e esse conflito se dão porque a dimensão do tempo criador da norma mediante esse retrabalho e/ou antecipação [re]questiona-a, nesse encontro/instante, e muda-a, de modo ínfimo ou não. Dito de outra maneira: ela (re)cria outros conhecimentos, normas; vale dizer, 
[re]cria outra [s]antecipação[ōes] em confronto com as antecipações da dimensão de média da norma, de seus conhecimentos.

\section{I. Comunicação e dimensão de média da norma: prevalência da atividade de conhecer}

$\mathrm{Na}$ atividade de trabalho real de treinar, que toma o lugar da atividade de trabalho real de ensinar, observamos que a linguagem é comunicação. Como tal, nega-se que a língua é a relação ao outro ou a relação em direção ao outro/ em direção ao "sujeito". O outro/"sujeito", no caso o aluno-operário, é colocado como aquele para quem os conhecimentos prévios são comunicados, os da dimensão de média da norma, o seu corpus de conhecimentos (i1). Ele deve conhecê-los, porém não retrabalhá-los, requestioná-los, pensá-los, refleti-los. Cabelhe, simplesmente, apropriá-los e aplicá-los nas atividades do novo modo de trabalho. Inspirando-nos em Arendt (2004), consideramos que, mediante o treinamento, buscar-se-ia a realização, exclusiva, da atividade de conhecer. Essa atividade dar-se-ia sob o crivo estrito do império da dimensão de média da norma, pela qual os conhecimentos científicos e técnicos (i1) são comunicados pelos critérios dos procedimentos de generalização e de padronização e de sua acumulação. Não haveria a distinção entre esses conhecimentos e aqueles que são de fato "lei" ", estes últimos no sentido de que não são passíveis desse retrabalho porque são raciocínios a fortiori, conforme examina Schwartz (2004, 2005). Indiscrimina-se esse caráter com o caráter de norma dos conhecimentos que são postos em dúvida, retrabalhados, (re)criados, em suma, renormalizados pela atividade de pensar imbricada na atividade de conhecer pela dimensão subjetiva da norma. Por tudo isso, a comunicação também toma o lugar da transmissão, visto aquela negação da língua e da relação ao outro que ela é. A palavra, aí, é um móvel com vista, exclusivamente, a um dado fim: no caso, o de treinar, sob aquela temporalidade econômica, em que os conhecimentos são tidos como dados acabados e acumulados, disponíveis à apropriação e ao consumo e a sua utilização imediata, de acordo com o novo modo de trabalho, que coloca novos usos de Si, do Homem, na esfera produtiva.

Gostaríamos, ainda, de salientar que, quando a língua é reduzida a instrumento ou móvel de comunicação, há no lugar da palavra, de acordo com Elias (1994), a comunicação de símbolos sonoros padronizados do código da língua, no caso daqueles conhecimentos prévios ao novo modo de trabalho. Dito de outro modo, comunicam-se os sentidos do código, que correspondem a conhecêlo, sob a dimensão de média da norma, e se os aplicam nas atividades de traba-

11. Sobre a distinção, no ato de transmitir, entre os caracteres da lei e os da norma dos conhecimentos, cf. Schwartz $(2004,2005)$. 
lho pelos alunos-operários. A atividade de trabalho real de treinar, ou o treinamento, nada mais seria que conhecer o tangível, o já conhecido e, tantas e tantas vezes, testado e verificado no(s) e pelo(s) modelo(s) de conhecimento(s) do i1. Assim sendo, o encontro seria o daquela redução da experiência para conhecer o i1, movendo-se, estritamente, no campo da dimensão de média da norma, conforme acima salientado. Assim, na atividade de trabalho real de treinar ou de treinamento não haveria espaço para a dúvida, o questionamento, e para os significados que essas atividades do pensamento dão a esses sentidos pela dimensão do tempo criador da norma. E não há esse espaço para essas atividades intelectuais porque elas foram banidas por essa redução da língua, da linguagem, a instrumento que nega a presença do outro, a sua manifestação. Vale dizer, porque ela nega a presença do "sujeito" e sua manifestação no encontro/instante entre experiência e conhecimento, entre i1 e i2.

Seguindo os rastros de Arendt (2004), podemos afirmar que, na atividade de trabalho real de treinar, haveria, de modo estrito, a atividade de conhecer, que conduz à posse de um novo conjunto de normas de conhecimentos disciplinares, técnicos e sociais (i1) exigido pelo novo modo de trabalho. Muda-se a posse de acordo com as circunstâncias, as conveniências e os interesses; no caso, as mudanças no uso de $\mathrm{Si}$ no trabalho, isto é, de acordo com as mudanças no governo de Si, do Ser vivo humano, do "Sujeito", no trabalho (Rosa, 2004). Em função disso, demandar-se-á ora mais, ora menos conhecimentos. Podemos dizer que o móvel dessa atividade é a quantificação articulada com o resultado, enquanto evidência, da obtenção dessa posse. Assim,

\section{0 mil horas de treinamento. Isso equivale a uma carga horária anual, em torno de 120 horas por trabalhador (num universo de 2.500 trabalhadores-operários, em 1987/início de 1992; e de 1500, em 1994). (Coordenador de Treinamento e Desenvolvi- mento do setor de Recursos Humanos).}

Contabiliza-se o resultado tido enquanto evidência dessa atividade de trabalho, aí se incluindo os antigos cursos de $1^{\circ}$ Grau (últimas séries) e de $2^{\circ}$ Grau. Todavia, na contabilização feita, o que está em jogo é a demonstração do acúmulo de conhecimentos enquanto meramente dados acabados tendo em vista essa posse para o cumprimento dessa demanda. E isso se dá graças à prevalência da atividade de conhecer sobre a atividade de pensar e, por conseguinte, as subsunções da língua e da transmissão pela comunicação e pelo treinamento. A generalização de demanda de avaliações dos trabalhadores, aí compreendidos os professores, é fruto dessa prevalência e dessas subsunções que se ancoram na dimensão de média da norma, com exclusão da outra dimensão da norma, a subjetiva e/ou a do tempo criador e, juntamente, da ativi- 
dade de pensar na atividade real de trabalho de ensinar. Desnecessário dizer que, em última instância, negam-se a presença do "sujeito" e sua manifestação naquele instante/encontro entre conhecimentos (i1) e experiência (i2), uma e outra calcadas na interdependência e na concomitância da atividade de pensar e de conhecer e na dupla dimensão da norma, em constante tensão.

\section{À guisa de conclusão}

Procuramos mostrar a diferença entre a atividade de trabalho real de ensinar e a atividade de trabalho real de treinar. Vimos que, em cada uma, a língua, a palavra, é que as torna factíveis. Na primeira atividade, há a tensão entre as duas dimensões da norma; já na segunda atividade, há o subdimensionamento e a submissão de uma delas, a da dimensão do tempo criador da norma, prevalecendo a dimensão de média da norma.

Gostaríamos, no momento, de retomar a questão da transmutação da atividade de trabalho real de ensinar em atividade de trabalho real de treinar, destacada no início do presente texto.

Observamos que, sem a dimensão do tempo criador da norma, não existiria a dimensão de média da norma, mesmo que esta sufoque e subdimensione a primeira. Como, então, trazer à luz a atividade de trabalho real de ensinar, que não é outra coisa senão a língua - a relação ao outro - e o encontro entre experiência e conhecimentos e, pois, a manifestação da presença do "sujeito"? Parecenos que é somente mediante essa relação que será possível prevalecer a atividade de pensar na relação com a atividade de conhecer e, com ela, a reflexão, a dúvida, o questionamento, as escolhas e as preferências, bem como o novo que dela pode surgir, no uso que cada um fará de si (o uso de si por si mesmo) ${ }^{12}$. Assim sendo, não haverá a prevalência de uma das dimensões da norma - no caso, a de média -, que configura a atividade de trabalho real de treinar, a qual torna a língua - a palavra - móvel ou instrumento de comunicação onde os conhecimentos são tidos como dados prontos, acabados e reduzidos ao utilitarismo cujos conteúdos têm em vista o seu consumo e a aplicabilidade imediatos no processo produtivo. Além disso, abstraem-se a presença e a manifestação do "sujeito" e a experiência de trabalho e o trabalho como experiência. Em suma, abstrai-se e descarta-se o próprio trabalhador-professor.

Os chamados cursos superiores a distância, também denominados cursos não presenciais, e outros assemelhados, a nosso ver, firmam e reafirmam a

12. Sobre o conceito de uso de si cf. Schwartz (1992, 2000a) e Rosa (2004) que ao longo do livro o articula em relação à situação imediata de trabalho real, considerando os testemunhos de trabalhadores. 
prevalência da dimensão de média da norma e, pois, a atividade de conhecer em detrimento da atividade de pensar e, juntamente, [re]afirmam a atividade de trabalho real de treinar e a comunicação. Por conseguinte, [re] afirmam essa abstração e esse descarte ${ }^{13}$ do trabalhador-professor - a sua experiência de trabalho e o trabalho como experiência.

A nosso ver, há nesses cursos a naturalização da abstração da não manifestação da presença do "sujeito" enquanto norma[tividade] que os configura, exprimindo-se mediante os termos distância e/ou não presencial. Vale dizer, há a naturalização da abstração da não manifestação da língua - relação em direção ao outro, ao "sujeito". Entretanto, salientamos, ao longo do artigo, que a manifestação da presença do "sujeito" dá-se, vis-à-vis, por quem ensina e por quem é ensinado. Ou seja: dá-se por essa presença e, pois, pelo "sujeito", presença esta que se ancora na palavra ou na língua - a relação ao outro/"sujeito" e ao terceiro -, no trabalho real de ensinar. Essas são condições sine qua non para o encontro entre experiência e conhecimentos e para a realização da interdependência das atividades de pensar e de conhecer nesse trabalho, que é o de forma[r]ção. Sem essas manifestações e essa relação não há a transmissão do i1, mas, sim, a sua comunicação como um conjunto de informaçôes padronizadoras e generalizadoras, visando ao treinamento cujo coroamento é a obtenção da certificação, como mais uma coisa, uma mercadoria, adquirida e portada pelo agente. A naturalização da abstração da não manifestação da presença do "sujeito" como norma(tividade) nos cursos não presenciais/a distância ainda exprime a não distinção entre forma(r)ção e treina(r)mento e promove a equivalência da atividade de pensar e da atividade de conhecer. Sob essa equivalência, há a dominância da atividade de conhecer subsumindo e subdimensionando a atividade de pensar e, por conseguinte, há a tendência da prevalência da dimensão de média da norma que, por sua vez, subsume e subdimensiona a sua outra dimensão, a do tempo criador ou a da dimensão subjetiva, e a antecipação que esta efetua.

No início do presente artigo, na introdução, colocamos entre aspas os termos "cursos", "cursinhos" e as designaçôes que lhes correspondem: de "capacitação", de "treinamento", de "atualização"e/ou "reciclagem". Assim o fizemos pelo fato de situarem-se sob a égide da separação entre as atividades de pensar e de conhecer, com a dominância desta última e de sua dimensão da norma, a de média, próprias da atividade do trabalho real de treinar. A nosso ver, o fato ocorrido no cotidiano, ao qual a seguir nos referimos, mostra essa dominância e sua recorrência no sistema de ensino regular e, fora dele, no social.

13. Cf. Rosa (2002, p. 20 I) que apresenta o descarte do trabalhador em função das mudanças no trabalho. Os cursos não presenciais ou a distância são frutos também destas mudanças. 
No decorrer do mês de abril do ano de 2007, uma estudante do curso de pedagogia de uma universidade particular falou-nos sobre o "estágio" que está sendo realizado por ingressantes do curso. Ela era uma dessas ingressantes.

Estávamos dentro do ônibus, sentadas, e conversávamos. Disse-nos que se dirigia à administração da faculdade em que ingressara porque dera uma confusão com o seu nome. Finalmente, tudo fora resolvido para que pudesse entregar os documentos para a realização do "estágio" e, junto, poder iniciar o curso de graduação em pedagogia. Explicou-nos que teria, indiretamente, bolsa de estudos, durante os anos de realização do curso, pois a bolsa é paga diretamente para a faculdade pelo governo. ${ }^{14}$ Estava contentíssima por não pagar o curso, a faculdade, bem como estava de acordo com o fato de realizar o "estágio", de imediato ao seu ingresso e início do curso, ou seja, sem antes de ter tido acesso à formação prévia (ao ingrediente 1), base à formação para a profissão de professor (aliás, de qualquer profissão). Não via nenhum problema nisso porque, conforme nos disse, havia realizado, num espaço de tempo de um mês, o "curso" de "capacitação", na própria faculdade, com vista a realizar o "estágio" em sala de aula. De tal modo era o seu entusiasmo e concordância, que se colocava já tendo essa formação prévia, graças a esse "curso" que já a situava, de acordo com suas palavras, como professora. Foi nesse contexto, sobretudo o de não pagamento do curso, que disse, veementemente:

Vou para a prática, vou ter a prática.

(Estudante de graduação, Curso de Pedagogia. Diário de Campo).

Colocamos-lhe a questão:

mas sem ter tido ainda a formação prévia? E nem minimamente? Um torneiro-mecânico tem a formação prévia para trabalhar como torneiro, profissionalmente [e assalariado], na fábrica. Só terá "a prática" se tiver a formaçãa $0^{15}$. O mesmo ocorre com o professor, seja qual for o nivel de ensino. (Autora. Diário de Campo)

De imediato, não concordou com o que disséramos.

$\mathrm{Na}$ inexistência de formação prévia (i1) antes da efetuação do estágio, sob o âmbito da atividade de trabalho real de treinar que se generaliza no sistema de ensino regular e no social, estão em jogo mais dois aspectos que foram observa-

14. Cremos que essa estudante se referia ao Programa denominado de Professor-Auxiliar instituído no sistema de ensino regular público, no nível fundamental, pelo governo do Estado de São Paulo. Cf. O Estado de S. Paulo, São Paulo, 20-6-2007, Caderno A, p. 2.

I5. Cf. nesse sentido: Bryan (2008); Gonçalves (200I); Souza (2006). Os autores mostram o aprendizado pelo trabalho (não assalariado) no decorrer da formação, porém já tendo o aprendiz tido acesso aos conhecimentos disciplinares. 
dos na análise do testemunho do Professor-operário. O primeiro refere-se à negação da temporalidade pessoal, ergológica, da estudante, e o segundo concerne à negação da temporalidade do acesso prévio aos conhecimentos específicos das disciplinas do corpus de conhecimentos, com protocolos e procedimentos variados em função do objeto de cada uma delas - das normas antecedentes da formação para o magistério do ensino fundamental e médio.

Esses dois aspectos são o encontro/instante entre conhecimentos (i1) e experiência (i2) que efetua cada estudante. Esse encontro/instante constitui-se também no trabalho prévio que realiza cada estudante em e na formação - o próprio acesso a esse corpus de conhecimentos -, sem o qual não haverá a experiência desse encontro na atividade real de trabalho de ensinar, quando no exercício da profissão de professor. O estágio funda-se nesse encontro que será modificado em/na atividade real de trabalho de ensinar pela dimensão do tempo criador da norma. Sem esse encontro anterior ou trabalho prévio, o estágio e a atividade real de trabalho de ensinar não se efetuam. Por conseguinte, o estágio pelo estudante somente é possível devido a esse encontro entre conhecimentos (i1) e experiência (i2), a esse trabalho prévio, que será modificado, de modo ínfimo ou não, [re]questionado, criando-se outras normas, conhecimentos, pela e na atividade real de trabalho de ensinar e mediante essa dimensão da norma. Isso significa que não há a dicotomia, entre, de um lado, teoria; e, de outro, "prática" e/ou teoria e trabalho ${ }^{16}$, graças a esse encontro/instante ou a esse trabalho prévio (normas antecedentes) que é [re]questionado, modificado, recriado na atividade real de trabalho de ensinar. Dizer "em dicotomia" é negar, senão apagar, aquelas temporalidades: a ergológica do estudante, no acesso às normas antecedentes da formação e à do próprio acesso onde tem lugar esse trabalho prévio ou a experiência para esse acesso, sem o qual nenhum trabalho real se realiza. Acreditamos que o "estágio" referido pela estudante orienta-se, no âmbito do conhecimento, por essa ideia de dicotomia que desconsidera, senão ignora, esse trabalho prévio efetuado pelo estudante na e pela formação, o qual sofrerá esse [re] questionamento na atividade de trabalho real de ensinar e, por conseguinte, desconsidera também esse encontro/instante.

Vale ainda reiterar que tanto a inexistência de formação prévia quanto a negação dessas temporalidades se dão devido àquela tendência à prevalência da atividade de trabalho real de treina[r]mento e da comunicação, em detrimento da atividade de forma[r] $]$ ção, da língua, relação ao outro e da transmissão, ocorrendo a subsunção da atividade de pensar pela atividade de conhecer. Essas prevalências ocorrem no social e, aí, no sistema regular ou não de ensino.

16. Cf., nesse sentido: Joazeiro (2002).

Pro-Posições, Campinas, v. 21, n. 3 (63), p. 155-172, set./dez. 2010 
Parece-nos que tanto os cursos denominados não presenciais e/ou a distância, cuja norma(tividade) se funda na naturalização da abstração da não manifestação do "sujeito", de sua presença - que, em suma, é a abstração da língua, relação ao outro ou em direção ao outro - quanto essa tendência e essa dominância vêm se arraigando para além da esfera imediata do trabalho: nos espaços do sistema de ensino, regular ou não, e no cotidiano. Disso tem-se, além da consequência do descarte do trabalhador-professor, de sua experiência de trabalho (do i1 e i2) e do trabalho como experiência, que se confluem, a do empobrecimento mental e intelectual por parte de quem ensina e de quem é ensinado, ou seja, da geração adulta e da geração jovem. Esse duplo empobrecimento acaba por incidir naquele encontro entre experiência e conhecimentos nas múltiplas situações da existência humana. E isso malgrado a aproximação e o encontro diuturno entre gerações.

\section{Referências bibliográficas}

ARENDT, Hannah. Pensamento e considerações morais. In: ARENDT, Hannah. Responsabilidade e julgamento. São Paulo: Companhia das Letras, 2004. p. 226-257, p. 375.

BRYAN, Newton Antonio Paciulli. Educação, processo de trabalho e desenvolvimento econômico. Campinas: Átomo e Alínea, 2008. p. 165.

ELIAS, Norbert. Qu'est ce que la socilogie? [s.1.]. De L' Aube, 1991. p. 223.

ELIAS, Norbert. Teoria simbólica. Oeiras: Celta, 1994. p. 149.

GONÇALVES, Paulo Celso Costa. Formação do trabalhador e ensino profissional. A Escola Profissional Masculina de Rio Claro. 2001. Dissertação (Mestrado em Educação) - Universidade Estadual de Campinas, Campinas. 189 p.

JOAZEIRO, Edna Maria Goulart. Estágio supervisionado. Experiência e conhecimento. São Paulo: ESETec, 2002. p. 171.

LANDA, Fábio. A loucura da língua e o assassinato do vivente. Pro-Posiçôes, Campinas, v. 13, n. 3(39), p. 11-17, set./dez. 2002.

ROSA, Maria Inês. Trabalho, subjetividade e poder. São Paulo: Letras \& Letras; EDUSP, 2002. p. 228.

ROSA, Maria Inês. Usos de si e testemunhos de trabalhadores. Com estudo crítico da Sociologia Industrial e da reestruturação produtiva. São Paulo: Letras \& Letras, 2004. p. 357.

ROSA, Maria Inês. Privilégio e apagamento do “sujeito". Educação: teoria e prática, Rio Claro, v. 18, n. 31, p. 87-102, jul./dez. 2008.

SCHWARTZ, Yves. Les ingrédients de la compétence: un exercice nécessaire pour une question insoluble. Éducation Permanente, Paris, n. 133, p. 9-34, abr. 1997. Tradução de Alain P. François, Revisão técnica de Maria Inês Rosa. Publicado: Educação \& Sociedade, Campinas, n. 65, p. 101-139, dez. 1998. 
SCHWARTZ, Yves. Langue, parole, usage de la langue. In: SCHWARTZ, Yves. Expérience et connaissance du travail. Paris, Messidor/Ed. Sociales, 1988. p. 224-233, p. 907.

SCHWARTZ, Yves. Travail et l'usage de soi. In: SCHWARTZ, Yves. Travail et philosophie. Convocations mutuelles. Toulose: Octares Ed., 1992, p. 43-66, p. 256. Publicado: revista ProPosiçōes, Campinas, v. 11, n. 2 (32).p. 34-50, jul. 2000a.

SCHWARTZ, Yves. Le travail comme expérience et les critères du taylorisme. In: SCHWARTZ, Yves. Le paradigme ergologique ou un métier de Philosophe. Toulouse: Octarès, 2000b. p. 333358, p. 763.

SCHWARTZ, Yves. Transmettre. Texto apresentado aos RENCONTRES APST-APRIT, 4. Université de Provence-Aix-Marseille I, France, 24 juin 2004. Mimeo, 12 páginas. Publicado: Revista Pro-Posiçōes, Campinas, v. 16, n. 3(48), p. 229-244, set./dez. 2005.

SOUZA, Dorival Pereira de. 'Novo' modelo de formação no SENAI. 2006. Dissertação (Mestrado em Educação) — Universidade Estadual de Campinas, Campinas. 126 p.

Recebido em 23 de julho de 2009 e aprovado em 19 de novembro de 2009. 